\title{
EDITORIAL
}

\section{Alergia Alimentaria}

Dra. Sylvia Cruchet M.

MSc Gastroenterología y Nutrición Pediátrica

Las alergias alimentarias (AA) son un conjunto de enfermedades en las que los síntomas son la respuesta inmunológica del organismo frente a un alergeno presente en algún alimento y ocurren en alrededor del 2,0 a 7,5\% de los niños. Las manifestaciones clínicas afectan al tracto gastrointestinal, respiratorio y/o piel, predominando las manifestaciones gastrointestinales en lactantes y niños menores. Se ha visto a nivel internacional que las AA van en aumento, específicamente, la alergia a la proteína de leche de vaca (APLV), que se presenta en un 2 a 5\% de los menores de 3 años de edad. En 2016, el INTA mostró que la incidencia de APLV fue de 4,9\% en lactantes menores de un año de un hospital público de Santiago y en Europa, se ha estimado un rango de 1,9 a $4,9 \%$ de APLV en lactantes menores de un año.

Un factor de riesgo para desarrollar alergias a los alimentos es (1) la historia familiar de atopia, (2) enfermedades alérgicas, (3) otras enfermedades alérgicas (dermatitis atópica) y (4) la exposición temprana a alérgenos alimentarios, como la proteína de leche de vaca, que se consume en altas cantidades durante la lactancia. Los lactantes, presentan barreras anatómicas y funcionales (acidez gástrica, enzimas intestinales) y barreras inmunológicas (IgA secretora), que se encuentran inmaduras en su desarrollo durante los primeros años de la vida, permitiendo el paso de antígenos alimentarios al torrente sanguíneo, por lo que existe una menor capacidad de "tolerancia" del sistema inmune intestinal.

Las respuestas inmunológicas a antígenos alimentarios, pueden ser: (1) reacciones mediadas por IgE y se caracterizan por un desarrollo rápido de los síntomas (segundos a pocas horas), que en su manifestación puede incluir shock anafiláctico, anafilaxia, urticaria, angioedema de piel y mucosas, eritema, síndrome de alergia oral, alergia gastrointestinal inmediata (vómitos explosivos, dolor abdominal y diarrea) y broncoespasmo; (2) reacciones no mediadas por lgE (inmunidad de tipo celular) y sus síntomas se desarrollan en horas o días e incluye la enterocolitis inducida por proteína alimentaria, protocolitis alérgica, enteropatía alérgica, dermatitis de contacto y enfermedad celiaca y (3) en algunas situaciones, existe más de un mecanismos fisiopatológico involucrado y se denominan mixtos e incluyen a la dermatitis atópica moderada o severa, esofagitis eosinofílica y/o gastroenteritis eosinofílica

¿Podemos hacer prevención primaria? La lactancia materna exclusiva hasta los 6 meses puede tener un rol en la prevención de enfermedades atópicas y sería el único factor modificable que puede aplicarse en la prevención primaria de la APLV. La eliminación de alimentos durante el embarazo no se recomienda en ningún caso dado que no hay evidencia que lo sustente para prevenir APLV.

En Chile, en los últimos 40 años, han aumentado todos los tipos de enfermedades de origen inmunológico, y entre ellas la alergia alimentaria y especialmente la APLV en el primer año de vida. Para prevenir la APLV y la alergia a otros alimentos es hacer el diagnóstico de certeza ya que los síntomas son inespecíficos y no existen síntomas ni signos patognomónicos de APLV. El diagnóstico diferencial dependerá de los sistemas afectados. La mayoría de las veces los síntomas ocurren luego de las primeras semanas de introducción de leche de vaca. Estos síntomas también se pueden presentar cuando el niño esta con lactancia materna y la madre consume leche.

Ha sido una preocupación permanente del Ministerio de Salud, este aumento en las alergias alimentarias. Ya que cuando se sospecha de un cuadro de este tipo en un lactante que no se encuentra con lactancia materna, se debe recurrir a formula extensamente hidrolizadas o de aminoácidos que son de alto costo para los padres. Con el propósito de unificar criterios para el diagnóstico se creó la "Guía Clínica: Alergia a Proteína de Leche de Vaca". Minsal, 2012; donde participaron pediatras gastroenterólogos, nutriólogos, inmunólogos y nutricionistas. Esta guía ha sido difundida a lo largo de la atención primaria de todo el país. La validación del uso de las guías se realizó en un estudio realizado por el INTA en 2015, donde además, se midió la incidencia de APLV en el primer año de vida en un hospital público, resultando ser de 4,9\%. Con esta alta incidencia de APLV, se decidió que a partir del año 2017 se entregara en el sector público de forma gratuita, formulas extensamente hidrolizadas o de aminoácidos a todos los niños que se encuentran con el diagnóstico de APLV y que no están recibiendo lactancia materna hasta los dos años de vida. El pronóstico de mediano y largo plazo de los pacientes con APLV es favorable ya que en la mayoría de los casos esta enfermedad se resuelve y los niños adquieren tolerancia durante los primeros 2 a 3 años de vida.

Se debe evitar estrictamente el uso de leches de otros mamíferos (oveja, cabra, bufala, yegua, burra), ya que existe el riesgo de reacciones alérgicas cruzadas. Los preparados vegetales, muy de moda en estos tiempos (soya, arroz o almendras) no se recomiendan para niños menores de dos años ya que no cubren apropiadamente los requerimientos nutricionales y si llegan a ser usados en mayores deben ser supervisados por nutricionista o nutriólogo. La leche de vaca sigue siendo un alimento completo, con el mejor aporte de calcio, proteína de excelente valor biológico y fuente de minerales y vitaminas indispensables para el crecimiento y desarrollo de niños sanos, además de ser económica y de fácil acceso a toda la población. 